John Emmanuel L. Ong, MD'

Emmanuel Tadeus S. Cruz, MD 1,2

Clydine Maria Antonette G. Barrientos, MD ${ }^{1,3}$

'Department of Otorhinolaryngology

Head and Neck Surgery

Manila Central University - Filemon D. Tanchoco Medical

Foundation Hospital

2 Department of Otorhinolaryngology

Head and Neck Surgery

Quezon City General Hospital

${ }^{3}$ Department of Otorhinolaryngology

Head and Neck Surgery

Makati Medical Center
Correspondence: Dr. Emmanuel Tadeus S. Cruz

Department of Otorhinolaryngology - Head and Neck Surgery Manila Central University - Filemon D. Tanchoco Medical Foundation Hospital

Epifanio de los Santos Ave., Caloocan City 1400

Philippines

Phone: (632) 3672031 loc 1212

Email: orlhns_mcu@yahoo.com

The authors declared that this represents original materia that is not being considered for publication or has not been published or accepted for publication elsewhere, in full or in part, in print or electronic media; that the manuscript has been read and approved by all authors, that the requirements for authorship have been met by each author, and that each author believes that the manuscript represents honest work.

Disclosures: The authors signed disclosures that there are no financial or other (including personal) relationships, intellectual passion, political or religious beliefs, and institutional affiliations that might lead to a conflict of interest.

Presented at the 35th Residents' Interesting Case Presentation Contest (1st place), March 30, 2016. MCU-FDTMF Hospital

Presented at the North East Otolaryngologists Consortium Interesting Case Presentation Contest (1st place), April 6, 2016 Quirino Memorial Medical Center.

Presented at the Philippine Society of Otolaryngology Head and Neck Surgery Interesting Case Contest. June 30, 2016. Unilab Bayanihan Center, Pasig City.

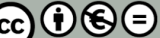

\title{
Unilateral Tonsilar Hypertrophy in a 4-Year-Old Girl with Focal Dermal Hypoplasia (Goltz Syndrome)
}

\begin{abstract}
Objective: To report a case of unilateral tonsillar hypertrophy resulting in severe Obstructive Sleep Apnea in a 4-year-old girl with focal dermal hypoplasia (FDH, Goltz or Goltz-Gorlin) Syndrome.
\end{abstract}

\section{Methods:}

$\begin{array}{ll}\text { Design: } & \text { Case Report } \\ \text { Setting: } & \text { Tertiary Private Teaching Hospital } \\ \text { Patient: } & \text { One }\end{array}$

Results: A 4-year-old girl with Goltz Syndrome (classical features of cutaneous and osteopathic disorders since birth) and unilateral tonsillar hypertrophy manifested with snoring and apneic episodes at two years of age. Polysomnography revealed severe Obstructive Sleep Apnea and Arterial Blood Gases revealed metabolic acidosis with hypoxemia. A tonsillectomy and adenoidectomy improved breathing, appetite and sleep with resolution of snoring and apneic spells and final tonsil histopathology revealed lymphoepithelial polyp.

Conclusion: A 4-year-old child with Goltz syndrome who developed severe obstructive sleep apnea due to tonsillar hypertrophy was presented. Otolaryngologists should be aware of this syndrome which may manifest with oral and mucosal lesions. Although rare, Goltz syndrome may be considered in the differential diagnosis of tonsillar hypertrophy especially in the presence of the inherent clinical features. Physicians should educate patients and address the co-morbidities associated with it through individualized treatment.

Keywords: Focal Dermal Hypoplasia, Unilateral Tonsillar Hypertrophy, Goltz Syndrome, Goltz-Gorlin Syndrome

Focal dermal hypoplasia (FDH), popularly known as Goltz or Goltz-Gorlin syndrome is a rare multisystem disorder first described by Goltz et al. in 1962 in a case report of 3 female patients who presented with similar cutaneous and skeletal abnormalities. ${ }^{1,2,3}$ This syndrome is registered under the National Organization for Rare Disorders and in a recent study done by Nicolas in 
2015, around 300 cases are registered in literature. ${ }^{5}$ To the best of our knowledge, other than a case of a 12-year-old girl with Goltz syndrome in the Philippine General Hospital by Nicholas in 2015, there is paucity of reports in Philippine literature. ${ }^{5} \mathrm{~A}$ keyword search using "focal dermal hypoplasia,"'Goltz syndrome" and "Goltz-Gorlin syndrome" in the Health Research and Development Information Network (HERDIN) database yielded negative results.

We present a case of unilateral tonsillar hypertrophy resulting in severe obstructive sleep apnea in a child with Focal Dermal Hypoplasia (FDH, Goltz or Goltz-Gorlin) Syndrome.

\section{CASE REPORT}

A 4-year-old Filipino girl born to non-consanguinous parents was the product of a 41-42 week gestation in a 28-year-old Gravida 3, Para 1 (0110) mother whose first pregnancy ended with early fetal loss at 7 months and whose second pregnancy terminated at 4 months, necessitating dilatation and curettage in both instances. Maintained on Progesterone and tocolytics for the entire duration of her third pregnancy, the mother had episodes of urinary tract infections in the $5^{\text {th }}-7^{\text {th }}$ months of gestation treated with vaginal suppositories. The girl was delivered via emergency low transverse caesarian section due to non-reassuring fetal status, and confined in the neonatal ICU for 5 days on antibiotics for meconium staining. There was no family history of congenital anomalies.

At birth, the child had atrophic skin lesions streaking over the forearms, chest and abdomen as well as ptosis of the left eyelid, low-set ears, dermal hypoplasia, nail dystrophy, and syndactyly of the $2^{\text {nd }}$ and $3^{\text {rd }}$ digit of the left foot, but no consults or interventions were made. Around 2 years of age, she was noted to have increased snoring with apneic episodes. At 4 years of age, she was finally brought to us by her mother for a progressively enlarging right tonsillar mass associated with snoring and frequent apneic spells.

Physical examination revealed short stature and thin build with height and weight measurements falling below $Z$ score -2 . There was ptosis of the left eyelid, sparse hair and a patch of parieto-occipital alopecia. (Figure 1) Oral cavity examination revealed complete dentition for age with notching and multiple dental caries and a 0.5 $\mathrm{cm}$ erythematous left lower lip mass. The right tonsil was hypertrophic, pinkish with a polypoid growth extending beyond midline while the left tonsil was unremarkable and confined within the anterior and posterior pillars. (Figure 2) Nasal endoscopic findings showed adenoid hypertrophy. Cutaneous lesions included hypo- and hyperpigmented macules on the forearms, chest and abdomen. There was also syndactyly of the $2^{\text {nd }}$ and $3^{\text {rd }}$ digit of the left foot. (Figure 3 )

Karyotyping yielded normal genetic constitution (46XX). Panoramic

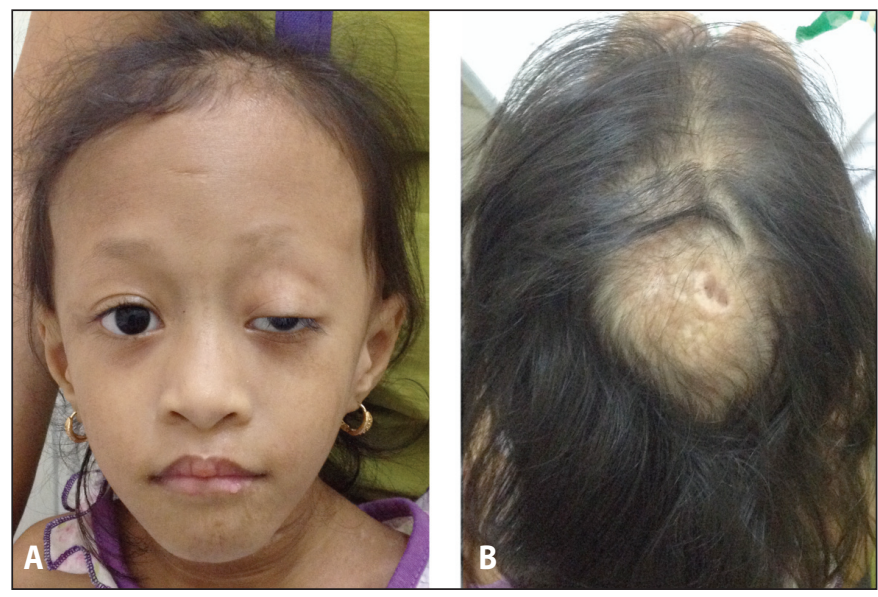

Figure 1. A. facial asymmetry, left eyelid ptosis, low-set ears, sparse eye brows and scalp hair B. a patch of parieto-occipital alopecia. (photos published in full, with permission)

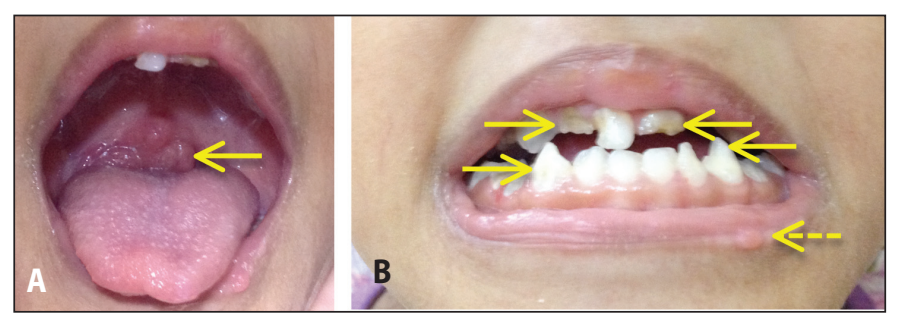

Figure 2. A. Right tonsillar hypertrophy with polypoid extension (arrow), prominent tongue papillae and slight clefting of the tip of the tongue B. Dental notching of maxillary incisors and mandibular canine and incisors (arrows) and left lower lip mass (dashed arrow).

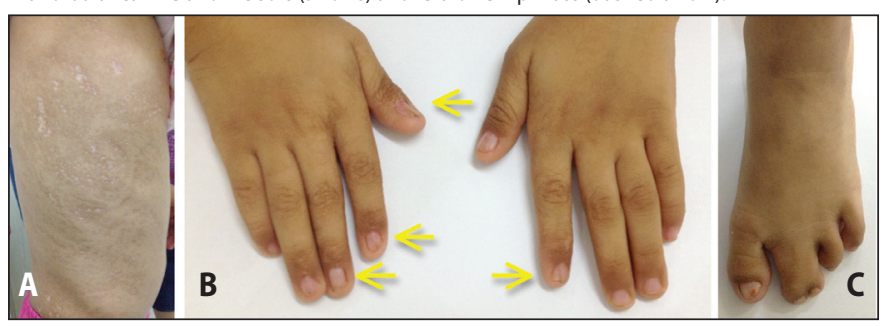

Figure 3. A. Cutaneous examination showed multiple hypo and hyper-pigmented macules over the chest and abdomen B. slightly dysplastic nails of the $1^{\text {st }}, 2^{\text {nd }}$ and $3^{\text {rd }}$ digits (arrows) C. Syndactyly affecting the $2^{\text {nd }}$ and $3^{\text {rd }}$ digit of the left foot.

$X$ ray revealed dental notching, deciduous teeth and appropriate dentition for age while 2D echocardiography findings were normal with an ejection fraction of $76 \%$. Polysomnography resulted in a diagnosis of severe Obstructive Sleep Apnea and behavioral insomnia of childhood. Arterial blood gases revealed metabolic acidosis with hypoxemia, while chest x-ray showed pneumonia and primary Koch's infection, which were treated. Unable to afford continuous positive airway pressure (CPAP) to alleviate chronic hypoxemia, she was eventually cleared to undergo tonsillectomy for removal of the tonsillar mass and adenoidectomy. Intraoperative findings confirmed the initial examination findings. (Figure 4)

She tolerated the procedure well with no postoperative 


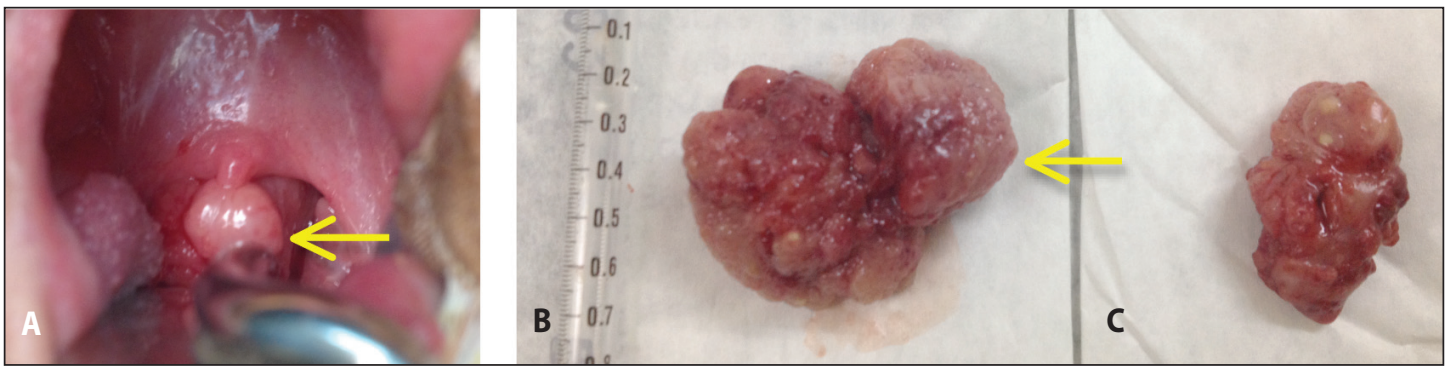

Figure 4. A. Intraoperative findings of a hypertrophic right tonsil with a polypoid growth extending beyond the midline B. right tonsil with polyp (arrow) C. left tonsil

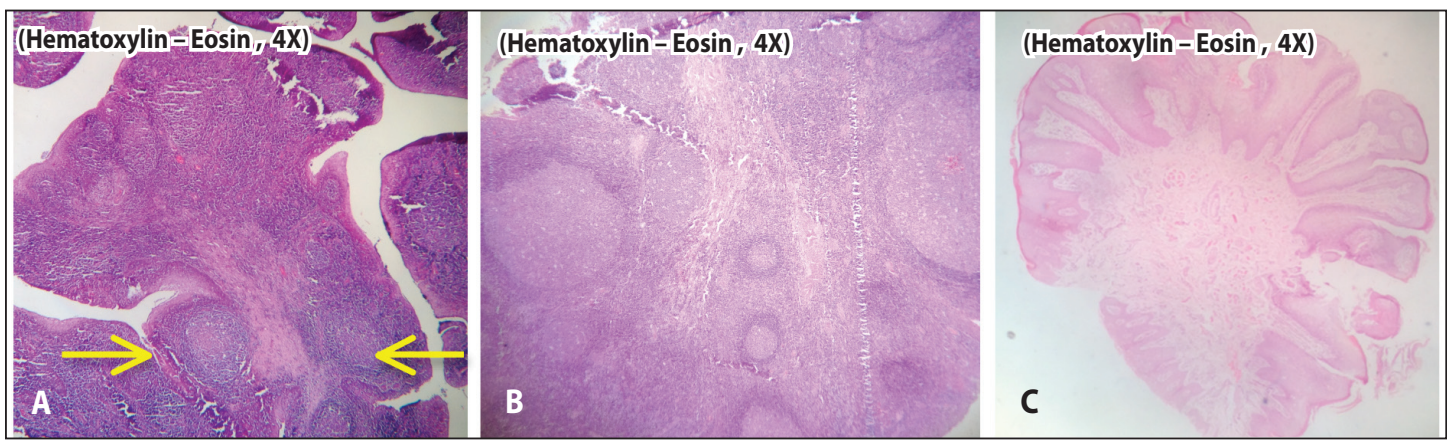

Figure 5. Histopathologic slide, scanning view (4x magnification), H\&E stain, showing A. lymphoepithelial polyp and subepithelial lymphoid nodules with active germinal centers (arrows) B. right tonsil with normal histology C. lower lip mass consistent with squamous papilloma.

complications. Her breathing, appetite and sleep pattern improved with resolution of snoring and apneic spells. The final histopathologic report revealed a lymphoepithelial polyp and subepithelial lymphoid nodules with active germinal centers, lower lip mass findings were consistent with squamous papilloma. (Figure 5)

\section{DISCUSSION}

FDH or Goltz-Gorlin syndrome should not be confused with GorlinGoltz syndrome which presents as multiple odontogenic keratocysts associated with Nevoid Basal Cell Carcinoma Syndrome. ${ }^{6}$ The genetic defect of Goltz syndrome lies in mutations of the porcupine homolog (PORCN) gene on the $X$ chromosome, with probable locus at Xp11.23. ${ }^{4}$

- 9 This mutation manifests as defects that can involve all 3 dermal layers-- ectoderm (skin, eyes), mesoderm (bones, teeth) and endoderm (various mucosa). ${ }^{78}$ The mnemonic FOCAL can be used to identify the key features of Goltz Syndrome: Female Sex; Osteopathy, striata; Coloboma; Absent ectodermis, mesodermis and neurodermis-derived elements; and Lobster claw deformity. ${ }^{6}$

The severity of defects is variable ranging from mild to mutilating manifestations. ${ }^{6}$ Women are predominantly affected and diagnosed $90 \%$ of the time primarily due to in-utero lethality in males. ${ }^{7}$ The variability is said to be due to random $X$-chromosome inactivation or lyonization within cells, hence females who have two $\mathrm{X}$ chromosomes are spared. 7 Males do present with the disease in 10\% of cases and this can be attributed to somatic mosaicism or due to a sporadic new mutation.?

There is no specific criteria to diagnose Goltz syndrome but the presence of skin lesions is considered essential followed by skeletal defects seen in $80 \%$ of patients. ${ }^{8}$ PORCN gene mutations causes defects in the WNT signaling pathway which is important in normal embryonic development of skin, bones, teeth and eyes. ${ }^{5}$ Hence, this would explain the primary features of Goltz syndrome: dermal hypoplasia that follows Blaschko lines which represent pathways of epidermal cell migration and proliferation during the development of the fetus, syndactyly, dental abnormalities and ptosis, which were present in our patient. ${ }^{5}$ However, due to polymorphism, not all features may be present in every individual affected by the syndrome. ${ }^{8}$

According to Jain et al., differential diagnoses for Goltz syndrome are: "(1) MIDAS (microphthalmia, dermal aplasia, sclerocornea), (2) Incontinentia Pigmenti, and (3) Rothmund Thomson syndrome."7 MIDAS syndrome usually shows "dermal atrophy typically limited to the upper half of the body and does not present with skeletal and extremity abnormalities" in contrast to our patient who presented with syndactyly and ptosis. Incontinentia pigmenti happens in stages which includes "a blistering rash at birth or early childhood, development of grey or brown skin patches of hyperpigmentation, which in adulthood 


\section{CASE REPORTS}

fades with time leaving lines of hypopigmentation."7 Finally, Rothmund Thomson syndrome generally "presents after 3 months of age with initial redness on the cheeks between ages 3 months and 6 months and then the rash spreads to the arms and legs with non-linear lesions."7 These 2 entities were ruled out because of the absence of their clinical manifestations in our patient.

As for the oral cavity findings, various authors have cited the occurrence of single to multiple raspberry papillomas which are usually not present at birth but develop with age and are typically found on skin and mucosal surfaces including the anus and vagina. ${ }^{4-6,9-14}$ Ghosh et al. reported that 6 out of 8 patients (75\%) with Goltz syndrome presented with the characteristic raspberry papillomas around the mouth. ${ }^{10}$ Ogunbiyi stated that these could also occur in the "larynx, eyelid margins, mouth, pharynx, tonsils, palate, gums, tongue and lips."15 The usual histology would show a "fibrovascular stalk covered with a layer of acanthotic stratified squamous epithelium resembling epidermis with extensive papillary folds."15 In our case, a lymphoepithelial polyp was attached to the right hypertrophic tonsil, and a lower lip mass was also excised with histopathology consistent with squamous papilloma.

In addition, DiSalvo et al. reported the case of a 38-year-old man with Goltz syndrome who presented with exophytic papillomatous masses from the right tongue base, left anterior tonsillar pillar, soft palate and small lesions on the upper and lower lips, which revealed papillary lymphoid hyperplasia following excision. ${ }^{16}$ Ogunbiyi reported a final histopathology of squamous papilloma in a 14-year-old girl with skeletal and cutaneous lesions who underwent tonsillectomy for kissing tonsils with obstructive sleep apnea. ${ }^{15}$ Nicolas reported on a 12-year-old girl with tonsillar hypertrophy occluding the pharynx coinciding with the syndrome but no surgical intervention was done. ${ }^{5}$ Indeed, oral and mucosal lesions may be apparent in Goltz syndrome and may compromise and obstruct the upper airway which may require tonsillectomy such as in our case.

Ancilliaries such as genetic studies and skin biopsy may be helpful but not essential in establishing Goltz syndrome since it is often diagnosed clinically. In our patient, chromosomal analysis revealed normal karyotype (46XX) while gene analysis used to detect mutations in the PORCN gene was not done. ${ }^{4}$ Skin biopsy would reveal dermal atrophy with disordered connective tissue and decreased collagen bundles and nests of adipose tissue extending into the upper dermis. ${ }^{5}$ Hence, clinical diagnosis in this case was established by the presence of skin, hair, oral cavity and extremity findings.

Patients with Goltz syndrome usually lead normal lives with normal to near normal intelligence. ${ }^{7}$ Management maybe individualized and may require multi-specialty care. ${ }^{5,7}$

In summary, we presented the case of a 4-year-old child with Goltz syndrome who developed severe obstructive sleep apnea due to adenotonsillar hypertrophy. Otolaryngologists should be aware of this syndrome which may manifest with oral and mucosal lesions. Although rare, Goltz syndrome may be considered in the differential diagnosis of tonsillar hypertrophy especially in the presence of the inherent clinical features. Physicians should educate patients with the condition and address the co-morbidities associated with it through individualized treatment.

\section{ACKNOWLEDGEMENTS}

The authors would like to thank Dr. Lyra Veloro from the Department of Otorhinolaryngology, Section of Pediatrics, Philippines Children's Medical Center and Dr. Eva Maria C. Cutiongco-dela Paz from the Department of Pediatrics, College of Medicine, Philippine General Hospital, University of the Philippines and Institute of Human Genetics, National Institute of Health, University of the Philippines for assisting in the diagnosis.

\section{REFERENCES}

1. Goltz RW, Petersone WC, Gorlin RJ, Ravits HG. Focal dermal hypoplasia. Arch Dermatol. 1962 Dec; 86:708-17. PMID: 13948891.

2. Goltz RW, Henderson RR, Hitch JM, Ott JE. Focal dermal hypoplasia syndrome. Arch Dermatol. 1970 Jan; 101(1):1-11. PMID: 5416790.

3. Goltz RW. Focal dermal hypoplasia syndrome: An update. Arch Dermatol. 1992 Aug; 128(8): 1108-11. PMID: 1497368

4. Bundra K, Sutton VR. National Organization for Rare Disorders. [Last update: 2013; Accessed 2016 Jan 28]. Available at: http://rarediseases.org/rare-diseases/focal-dermal-hyoplasia.

5. Nicolas ME, Gonzales-Carait PK. A case of Goltz syndrome. Indian J Paediatr Dermatol. 2015; 16 (3): 170-172. DOI: 10.4103/2319-7250.160664.

6. Soccio LC, Butler DF, Chan EF, Elston DM, Goltz RW, Lee W. Medscape: Focal Dermal Hypoplasia Syndrome. [Last update: 2014; accessed 2016 Jan 28]. Available at: http://emedicine.medscape. com/article/1110936-overview.

7. Jain A, Chander R, Garg T, Nikita, Shetty GS. A rare multisystem disorder: Goltz syndrome - Case report and brief overview. Dermatol Online J. 2010 Jun 15; 16(6): 2. PMID: 20579457.

8. Bharani S, Thakkar S. A case report of focal dermal hypoplasia-Goltz syndrome. Indian Dermatol Online J. 2013 Jul-Sep; 4(3): 241-243. DOI: 10.4103/2229-5178.115535; PMID: 23984248 PMCID PMC3752490.

9. Sarkar S, Patra C, Das A, Roy S. Goltz syndrome: A newborn with ectrodactyly and skin lesions. Indian J Dermatol. 2015 Mar-Apr; 60 (2): 215. DOI: 10.4103/0019-5154.152608; PMID: 25814752 PMCID: PMC4372956.

10. Ghosh SK, Dutta A, Sarkar S, Nag SS, Biswas SK, Mandal P. Focal dermal hypoplasia (Goltz syndrome): A cross-sectional study from Eastern India. Indian J Dermatol. 2017; 62 (5): 498 504. DOI: 10.4103/ijd.IJD 317 17.

11. Gammaz H, Amer A, Adly A, Mohsen A. Focal dermal hypoplasia (Goltz syndrome): A case report and review of literature. Egyptian Dermatology Online Journal. 2010 Jun; 6 (1): 13.

12. Riyaz N, Riyaz A, Chandran R, Rakesh SV. Focal dermal hypoplasia (Goltz syndrome). Indian J Dermatol Venereol Leprol. 2005 Jul-Aug; 71 (4); 279-281. PMID: 16394441.

13. Kadyan R, Al-Abdulrazzaq A, Najem N. Focal dermal hypoplasia (Goltz syndrome). The Gulf Journal of Dermatology and Venereology. 2010 Oct; 17 (2): 58 - 60.

14. Braun-Falco O, Plewig G, Wolff HH, Burgdoff WHC. Malformations and Genetic Disorders: Focal Dermal Hypoplasia. $2^{\text {nd }}$ Ed. Revised. Dermatology. Berlin Heidelberg New York: Springer. 2000. P 833. DOI: 10.1007/978-3-642-97931-6.

15. Ogunbiyi AO, Adewole IO, Ogunleye O, Ogunbiyi JO, Ogunseinde OO, Baiyeroju-Agbeja A, et al. Focal dermal hypoplasia: a case report and review of literature. West Afr J Med. 2004 Mar: 346-349. PMID: 15008304

16. DiSalvo DS, Oberman BS, Warrick Jl, Goldenberg D. Pharyngeal presentation of Goltz syndrome: A case report with review of literature. Head Neck Pathol. 2016 Jun; 10 (2): 188-191. DOI: 10.1007/ s12105-015-0667-4; PMID: 26577212 PMCID: PMC4838964. 